\title{
Conceptual Model Development for a Knowledge Base of PID Controllers Tuning in Open Loop
}

\author{
José Luis Calvo-Rolle ${ }^{1}$, Ramón Ferreiro García ${ }^{1}$, Antonio Couce Casanova ${ }^{1}$, \\ Héctor Quintián-Pardo ${ }^{1}$ and Héctor Alaiz-Moreton ${ }^{2}$ \\ ${ }^{1}$ University of Coruña \\ ${ }^{2}$ University of León \\ Spain
}

\section{Introduction}

In the area of control engineering work must be constant to obtain new methods of regulation, to alleviate the deficiencies in the already existing ones, or to find alternative improvements to the ones that were being used previously. This huge demand of control applications is due to the wide range of possibilities developed to this day.

Regardless of this increasing rhythm of discovery of different possibilities, it has been impossible at this moment to oust relatively popular techniques, as can be the 'traditional' PID control. Since the discovery of this type of regulators by Nicholas Minorsky (Mindell (2004) and Bennett (1984)) in 1922 to this day, many have been the works carried out about this controller. In this period of time there was an initial stage, in which the resolution of the problem was done analogically and in it the advances were not as notable as have been since the introduction of the computer, which permits to implement the known direct digital control structure Auslander et al. (1978), illustrated in figure 1.

Since then, the regulators have passed from being implemented in an analogous way to develop its algorithm control digitally, by signal digital processors. As well as carrying out the classic PID control in digital form, its development based on computer allows adding features to the regulator that with difficulty could have been obtained analogically.

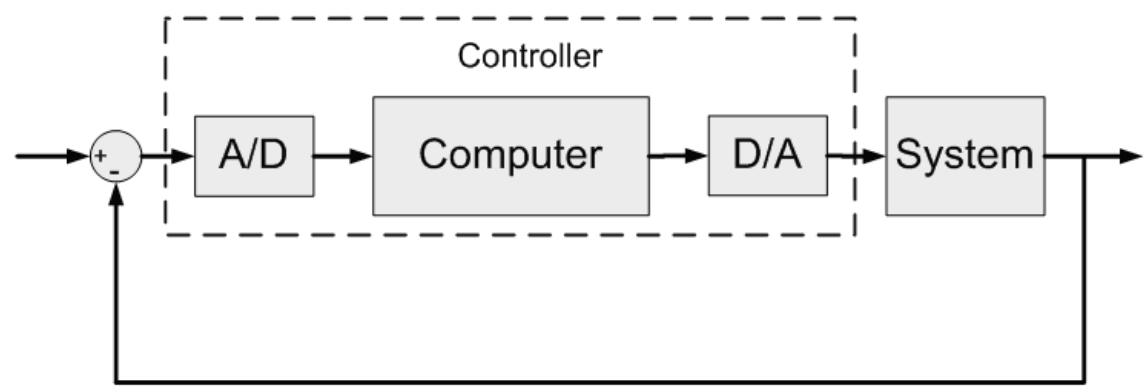

Fig. 1. Structure of direct digital control 
It must be said there exist usual control techniques for the processes in any area, in which innovations have been introduced. But nevertheless, the vast majority of these techniques in their implementation employ PID traditional controllers, although in an improved way, increasing the percentage of use around 95\% Astrom \& Hagglund (2006). Its use is still very high due to various reasons like: robustness, reliability, relative simplicity, fault, etc.

The great problem of the PID control is the adjustment of the parameters that it incorporates. Above all in its topology Astrom \& Hagglund (2006) Feng \& Tan (1998), as a consequence of the investigations carried out in the area, the contributions made by specialists have been many, existing among them many methods to obtain the parameters that define this regulator, achieved through different ways, and working conditions pertaining to the plant being controlled. It must be highlighted that the methods developed to obtain the terms which in occasions are empiric if they are always directed to optimise defined specifications; the negative thing is that frequently when some are improved others get worse.

It is necessary to highlight that the empirical methods have been the first in to be discovered and normally they are the ones who are first learnt, in the training of technicians in this discipline. In this sense the parameters obtained in this manner through the application of formulas of different authors, are a starting point of adjustment of the regulator, being normally necessary to have to do fine adjustment.

Regardless of what has been said, in practice there is a big variety of regulators working in the industry with an adjustment far from what can be considered optimum Astrom \& Hagglund (2006). This fact is originated among other reasons due to a lack of adjustment techniques by the users.

This fact creates the necessity to employ intelligent systems, due to the demand of a better performance and resolution of complex problems both for men as well as for the machines. Gradually the time restrictions imposed in the decision making are stronger and the knowledge has turned out to be an important strategic resource to help the people handling the information, with the complexity that this involves. In the industry world, intelligent systems are used in the optimization of processes and systems related with control, diagnosis and repair of problems. One of the techniques employed nowadays are knowledge based systems, which are one of the streams of artificial intelligence.

The development of knowledge based systems is very useful for certain knowledge domains, and also indispensable in others. Some of the more important advantages that the knowledge based systems offer are the following:

- Permanence: Unlike a human expert, a knowledge based system does not grow old, and so it does not suffer loss of faculties with the pass of time.

- Duplication: Once a knowledge based system is programmed we can duplicate countless times, which reduces the costs.

- Fast: A knowledge based system can obtain information from a data base and can make numeric calculations quicker than any human being.

- Low cost: Although the initial cost can be high, thanks to the duplication capacity the final cost is low.

- Dangerous environments: A knowledge based system can work in dangerous or harmful environments for the human being.

- Reliability: A knowledge based system is not affected by external conditions, a human being yes (tiredness, pressure, etc). 
- Reasoning explanation: It helps justify the exits in the case of problematic or critical domain. This quality can be employed to train personnel not qualified in the area of the application.

Up to now the existing knowledge based systems for resolution of control systems have reduced features (Pang (1991) Wilson (2005) Zhou \& Li (2005) Epshtein (2000) Pang et al. (1994) Pang (1993)), summarizing, in application of the method known as "Gain Schedulling" ?, which is based in programming the profits of the regulator with reference to the states variables of the process. For the cases in which the number of control capacities have increased, the knowledge based system, is applicable to specific problems. There is the possibility to implement knowledge based systems programming them in the devices, but without taking advantage of the existing specific tools of Knowledge Engineering Calvo-Rolle (2007) Calvo-Rolle \& Corchado (n.d.).

In accordance with what has been said, the development of a PID conceptual model is described in this document to obtain the parameters of a regulator PID with the empirical adjustment method in an open loop; feasible in the great majority of cases in which such method is applicable. The model has been developed for six groups of different expressions (formulas) with highly satisfactory results, and of course expandable to more following the same methodology.

The present document is structured starting with a brief introduction topology PID regulator employed, along with the traditional technique of which the conceptual method is derived, an explanation of the method proposed that is divided in three parts: In the first part the tests done to representative systems are explained, in the second part how the rules have been obtained and in the third how the knowledge has been organised. It concludes with the validation of the proposed technique.

\section{PID controller}

There are multiple forms of representation of the PID regulator, but perhaps the most extended and studied one is the one given by equation 1 .

$$
u(t)=K\left[e(t)+\frac{1}{T i} \int_{0}^{t} e(t) d t+T d \frac{d e(t)}{d t}\right]
$$

where $u$ is the control variable and $e$ is the error of control given by the $e=y_{S P}-y$ (difference between the specified reference by the entry and exit measured of the process). Therefore, the variable of control is the sum of three different terms: $P$ which is proportional to the error, $I$ which is proportional to the integral of the error and $D$ which is proportional to the derivative of the error (expression 2). The parameters of the controller are: the gain proportional $K$, the integral time $T_{i}$ and the derivative time $T_{d}$. If the function transfer of the controller is obtained and a representation of the complex variable is done, the form is the one illustrated in expression 2.

$$
G_{C}(s)=\frac{U(s)}{E(s)}=K\left(1+\frac{1}{T_{i} \cdot s}+T_{d} \cdot s\right)
$$

There are several forms for the representation of a PID regulator, but for the implementation of the PID regulator used, defined in the previous formula and more commonly known as the Standard format Astrom \& Hagglund (2006) Feng \& Tan (1998), shown in the form of blocks in figure 2. 


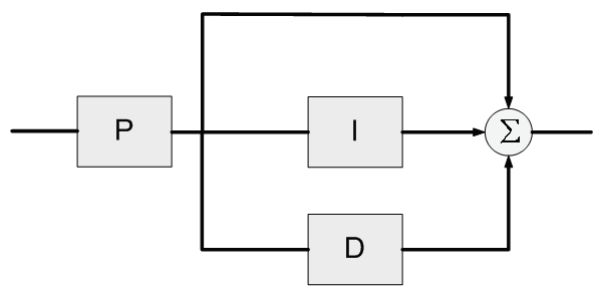

Fig. 2. PID regulator in standard topology

Infinite are the industrial processes whose normal function is not the adequate for certain applications. This problem, in many cases, is resolved through the employment of this regulator, with which defined specifications are obtained in the control of processes leading to optimum values for what was being done. The adjustment of this controller is carried out varying the proportional gain and the integral and derivative times.

\section{Adjustment of the open loop of PID regulators}

It is true that to this day there are analytical methodologies to obtain the parameters of a PID regulator, with the aim of obtaining an improved one or various specifications. From a chronological point of view, the empirical procedures were born before the obtaining of the parameters, and currently they are still used for various reasons like: the parameters are obtained in an empiric way, they are simple techniques, a given characteristic is optimized, good results are obtained in many cases, there is usually always a rule for the case that is trying to be controlled, etc.

\subsection{Steps to obtain the parameters}

The empiric techniques are based on the following steps:

1. Experimental establishment of certain characteristics of the response of the process that can be carried out with the plant working in open loop.

2. Application of formulas depending on the data previously obtained, to get the parameters of the regulator, with the aim that the function of the plant with the controller is within certain desired specifications.

\subsection{Adjustment criteria}

In the second stage the fact of situating the process within some desired specifications is stressed. From the point of view of the empiric adjustment it makes sense to talk about two types of principal specifications of the system in open loop, which are the ones stated hereafter:

1. Set point control: this specification indicates the capacity of the regulated system to achieve the changes made in the reference value.

2. Load disturbance: consists in the capacity of the system to attenuate possible noises or disturbances the charge/ load in a constant value of the reference value desired.

In figure 3 two examples can be observed of a system regulated by two PID controllers, adjusted to optimize both specifications previously mentioned. To the regulated systems a unit step is introduced, and after some time a disruption is provoked. As can be seen in the 


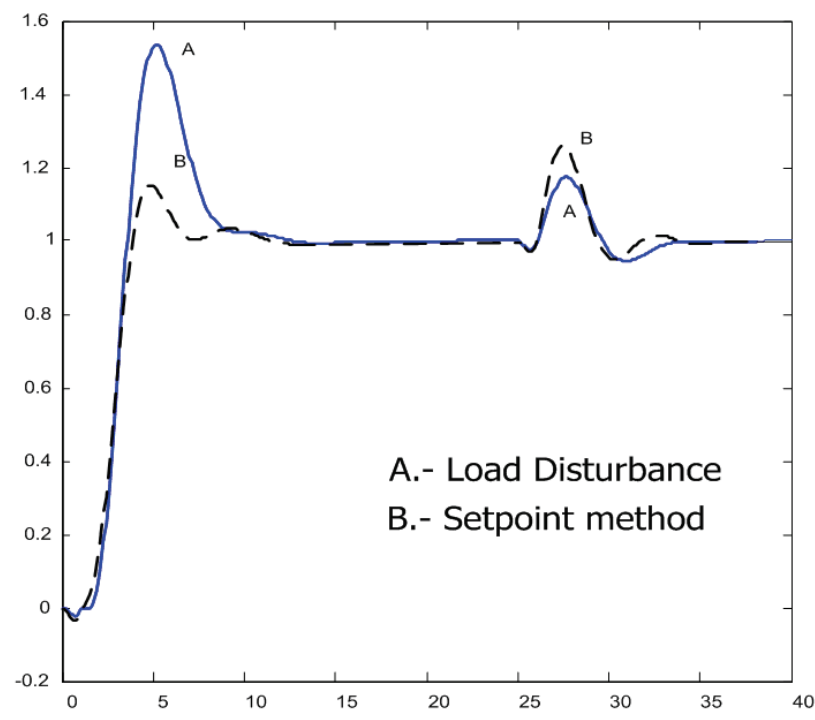

Fig. 3. Comparative between the Set point and Load disturbance response methods

curve identified as A corresponds to an adjusted regulator to improve the load disturbance criterion and, clearly the disturbance has less effect than in the set point response. With reference to curve $B$, the object was to regulate the system to improve set point control criterion, and it is done in a more effective way, because in the case of the initial step the temporary response is better than curve $\mathrm{A}$, however it must be highlighted that in the disturbance the sensitivity is higher for curve $B$.

If various formulas are employed in the tuning, the one chosen will be the one with a more prudent response within the specification that is intended to achieve, and after that increasing or decreasing the influence of the parameters of the controller until the response requested is reached, avoiding to take the plant to a non desired functioning area.

After this, most different tuning criteria are discussed, making a classification according to experimental testing of the response features of the system carried out in open loop.

\subsection{Measurements of the characteristics of the response of the process}

Within the steps to follow mentioned earlier, to obtain the parameters of the PID regulator, of them, in which the purpose is to measure characteristics of the response of the process, can be done in different ways, by obtaining different results in some cases and very similar in others. These ways to obtain process characteristics are explained in the next sections called Measurement $A$ and MeasurementB.

\subsubsection{Measurement A}

The first method to get the parameters is based on the response of a system with a unit step input, similar to the one shown in figure 4.

This is the typical output of industrial processes with a unit step input, and that can be usually known as reaction curve. It gets near the response of a first order model with delay whose transfer function is the one shown in expression 3. 


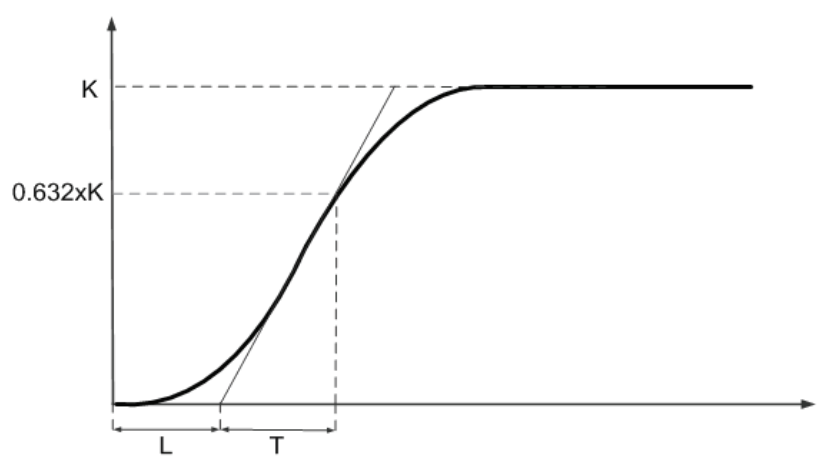

Fig. 4. Measurement A

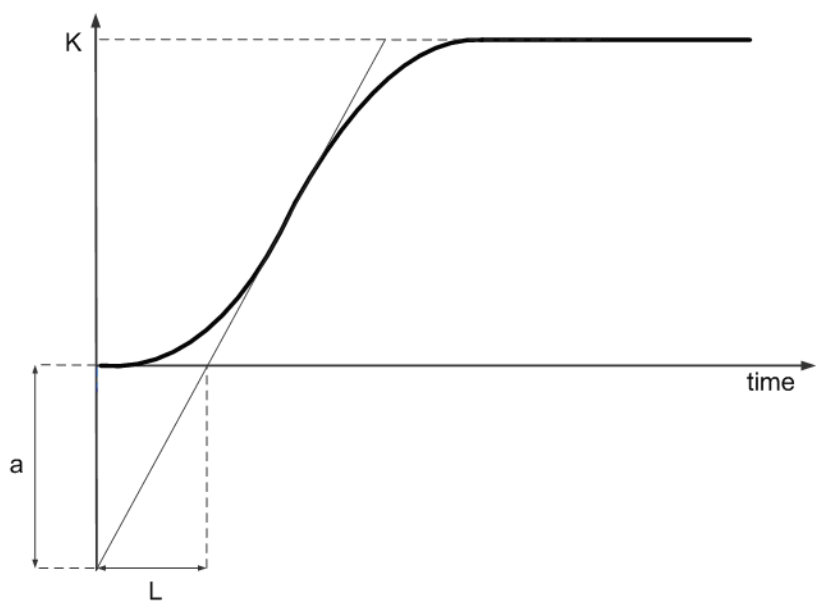

Fig. 5. Measurement B

$$
G(s)=\frac{K}{1+T \cdot s} e^{-s \cdot L}
$$

The parameters $\mathrm{L}$ and $\mathrm{T}$ come from drawing a straight line in the point of maximum slope of the curve. $\mathrm{L}$ is found where the mentioned straight line cuts the axis of $\mathrm{X}$ and $\mathrm{T}$ comes from prolonging the straight line up to the cut with the corresponding horizontal to $63.2 \%$ of the value of the gain $\mathrm{K}$ of the system (steady state value with a unit step input), cutting point in which is situated the sum of the $\mathrm{L}$ and $\mathrm{T}$ in its $\mathrm{X}$ coordinate.

\subsubsection{Measurement B}

In this case, there is the same response than in the last case, what occurs is that the measurement is made for a different approximation. The graphic in which the measurement is made is shown in figure 5.

As it can be observed what is done in this case is prolong the line with the greater slope up to its cut with the $\mathrm{Y}$ axis, value which is defined as "a". And so a model with two parameters 
is obtained, with one transfer function represented by an integrator with a pure delay. In this case the system gets close to the transfer function according to the expression 4 .

$$
G(s)=\frac{a}{L \cdot s} e^{-s \cdot L}
$$

\subsection{Parameters calculation through application of formulas}

Once the characteristics of the response of the process have been measured and it is acknowledged what specification wants to be optimized, the following is to apply formulas developed to fulfil the description sought, bearing in mind the scopes of application for which they were obtained. The application range for the case of empiric adjustment in an open loop comes defined usually by the existing relationship between the time delay $\mathrm{L}$, and the time of increase $\mathrm{T}$ of the system with unit step input.

Different authors propose expressions, in function of the characteristics of the transient response measured, for the achievement of the parameters of the regulator. It must be highlighted that there are multiple expressions given, that work in an adequate form in certain cases for which they were developed. It is frequent also that the manufacturers of controllers deduce their own expressions that work satisfactory above all with the products that they manufacture and especially for those applications to which they are destined. Is must highlighted that there are no general equations that always work well, because of this it will be necessary to select the expressions that best adjust in each specific case to the control that is intended.

In this case study there are gathered those more known and usual ones Ziegler (1942) Kaya (1988) Chien (1952) that are employed in the achievement of the parameters of the PID regulators, even though the methodology followed can be used for any case. In table 1 the different expressions are used in the present study are shown, together with the scope of application in each case.

\section{Design rules of PID regulators in open loop}

In the first part of this section it is made a sweep at the different expressions of achievement of parameters of the PID regulator previously mentioned, in which the systems are controlled with this type of regulator, with the aim of obtaining some generic design rules, or in their case particular rules for certain types of systems.

Due to the general character of the rules it will be necessary to employ for them significant systems. In this aspect it has been opted to use a known source in this scope, which is the Benchmark of systems to control PID developed by Åström and Hagglund Astrom (2000). In this source a collection of systems is presented that: are usually employed in the testing of PID controllers, these systems are based in countless sources of importance and also the immense majority of the existing systems adapt to some of those included in this source.

\subsection{Benchmark systems to which open loop empiric adjustment is not applicable}

There are a set of systems included in the Benchmarking to which the empiric adjustment in open loop is not applicable. If for instance there is a system whose transfer function is the expression 5, which deals with a system of first order.

$$
G(s)=\frac{1}{s+1}
$$




\begin{tabular}{|c|c|c|c|c|}
\hline Method & $K_{p}$ & $T_{i}$ & $T_{d}$ & Application range \\
\hline Ziegler-Nichols & $\frac{1.2}{a}$ & $2 \cdot L$ & $0.5 \cdot L$ & $0.1 \leq \frac{L}{T} \leq 1$ \\
\hline $\begin{array}{l}\text { Kaya-Scheib Set } \\
\text { point regulation } \\
\text { minimize IAE }\end{array}$ & $\frac{0.95}{K}\left(\frac{T}{L}\right)^{1.04432}$ & $\frac{T}{0.9895+0.09539 \frac{L}{T}}$ & $0.50814 \cdot T\left(\frac{L}{T}\right)^{1.08433}$ & $0 \leq \frac{L}{T} \leq 1$ \\
\hline $\begin{array}{l}\text { Kaya-Scheib Set } \\
\text { point regulation } \\
\text { minimize ISE }\end{array}$ & $\frac{0.71959}{K}\left(\frac{T}{L}\right)^{1.03092}$ & $\frac{T}{1.12666-0.18145 \frac{L}{T}}$ & $0.54568 \cdot T\left(\frac{L}{T}\right)^{0.86411}$ & $0 \leq \frac{L}{T} \leq 1$ \\
\hline $\begin{array}{l}\text { Kaya-Scheib Set } \\
\text { point regulation } \\
\text { minimize ITAE }\end{array}$ & $\frac{1.12762}{K}\left(\frac{T}{L}\right)^{0.80368}$ & $\frac{T}{0.99783-0.02860 \frac{L}{T}}$ & $0.42844 \cdot T\left(\frac{L}{T}\right)^{1.0081}$ & $0 \leq \frac{L}{T} \leq 1$ \\
\hline \begin{tabular}{|lr} 
Chien, & Hrones \\
y Reswick & load \\
disturbances & $(0 \%$ \\
Overshoot $)$ & \\
\end{tabular} & $\frac{0.95}{a}$ & $2.4 \cdot L$ & $0.42 \cdot L$ & $0.11 \leq \frac{L}{T} \leq 1$ \\
\hline \begin{tabular}{|lr} 
Chien, & Hrones \\
y Reswick & load \\
disturbances & $(20 \%$ \\
overshoot $)$ & \\
\end{tabular} & $\frac{1.2}{a}$ & $2.0 \cdot L$ & $0.42 \cdot L$ & $0.11 \leq \frac{L}{T} \leq 1$ \\
\hline $\begin{array}{lrr}\text { Chien, } & \text { Hrones y } \\
\text { Reswick Set } & \text { point } \\
\text { regulation } & \quad(0 \% \\
\text { Overshoot }) & & \\
\end{array}$ & $\frac{0.6}{a}$ & $T$ & $0.5 \cdot L$ & $0.11 \leq \frac{L}{T} \leq 1$ \\
\hline 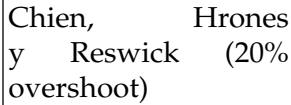 & $\frac{0.95}{a}$ & $1.4 \cdot T$ & $0.47 \cdot L$ & $0.11 \leq \frac{L}{T} \leq 1$ \\
\hline
\end{tabular}

Table 1. Expressions of parameters of authors and scopes of application

Analyzing its output after introducing unit step, as can be seen in figure 6, the delay time L is inexistent. This leads to two consequences: the first is that it would be out of range for all the cases contemplated in the case study, and the second is that the parameters that would depend on $\mathrm{L}$ in the expressions is zero.

If there is a system with a transfer function as the one in the expression 6, which is an unstable system, when introducing a step type input, in no case it will not offer a limited exit and in consequence there is no $\mathrm{L}$ and $\mathrm{T}$ to introduce in different expressions.

$$
G(s)=\frac{1}{s^{2}-1}
$$

Another possibility within the contemplated functions in the Benchmark is the systems that possess an integral action like the one in expression 7

$$
G(s)=\frac{1}{s^{2}+s}
$$

If a step input is introduced, the output has a form like the one indicated in figure 7. In it clearly it can be appreciated, that the output tends to infinite (saturation in real systems), and the time necessary raise time $\mathrm{T}$ cannot be obtained in the expressions to obtain the parameters, and therefore it is not applicable. 


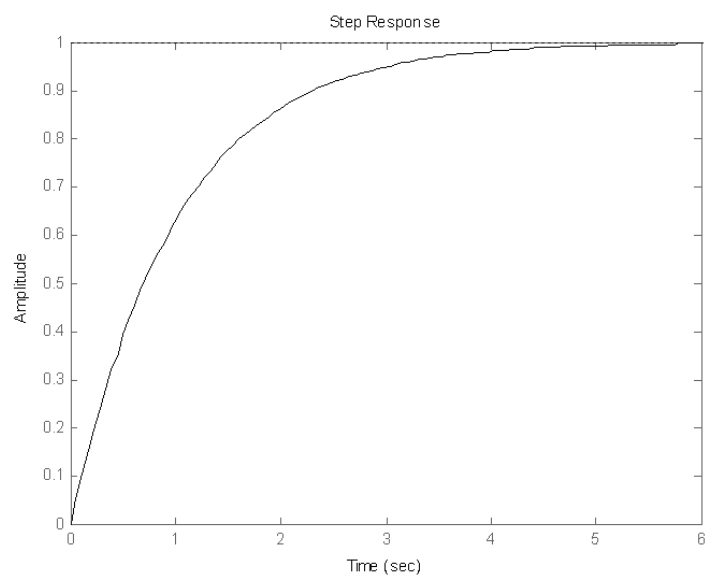

Fig. 6. First order system step response

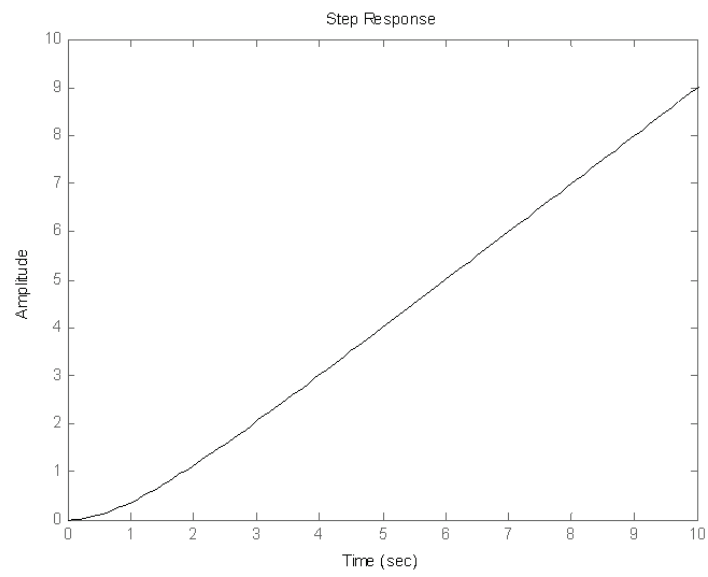

Fig. 7. System with integral action step response

\subsection{Benchmark systems to which empiric adjustment in open loop is applicable}

Apart from the types of systems that are found in some of the examples of the previous section, the rest can be regulated by a controller PID applying the empiric adjustment in open loop to obtain its parameters. If there is a transfer function like the one in expression 8 , and an input step is introduced, the response value of the system is the one of figure 8 , the so called reaction curve.

$$
G(s)=\frac{1}{(s+1)^{2}}
$$




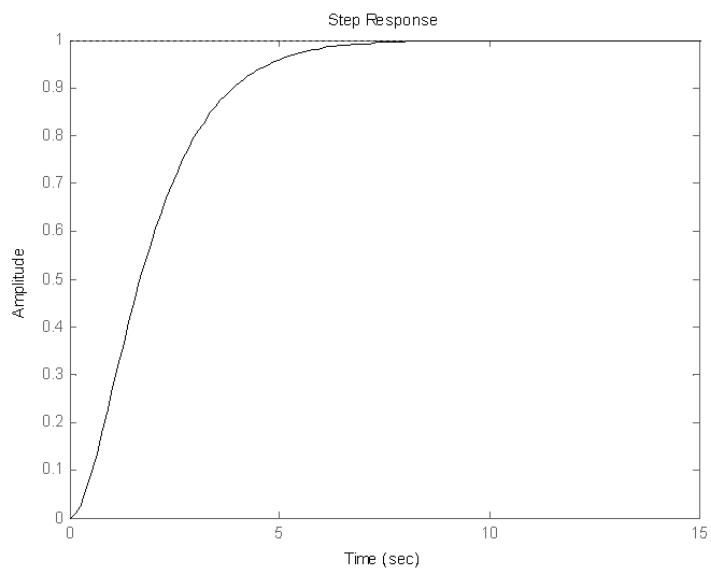

Fig. 8. Step response with typical reaction curve output

The features are set from the response of the process, in the graph of figure 8 obtaining in this case a value of $L=0.2817$ and of $T=2.7183$, what originates a relation $L / T=0.1036$, that according to the application ranges, all the groups of expressions are viable except Chien, Hrones and Reswick expressions. Nevertheless analysis will be carried out in all the cases contemplated.

\subsection{Analysis of the methods applied to obtain the rules}

Having obtained the reaction curve and in consequence the characteristics of the response of the system, regulating it with the different expressions in the case study proceeds, extracting significant specifications like: response time, peak time, overshoot and settle time.

All the tests will be carried out on all the systems proposed Åström in Benchmark in which they are applicable, to check the results and be able to extract conclusions from which rules will be obtained. If system of the expression 8 is regulated, the results obtained are illustrated in figures 9 and 10.

\section{PID controller conceptual modeling}

The conceptual model of a domain consists in the strictest organization possible of knowledge from the perspective of the human brain. In this sense for the domain that is being dealt with in this case study, a general summarized model is proposed and shown in figure 11.

As can be observed it is divided in three blocks:

- Organization of the existing rules: In this block the aim is to organise the existing rules of the types of expressions, scopes of application range, change criteria in the load disturbance or follow up of the set point control criterion, etc.

- Organization of existing knowledge with new rules: This block is the meeting point between the other two, and it aims to organise the existing knowledge in an adequate way for which it will be necessary to create new rules. 

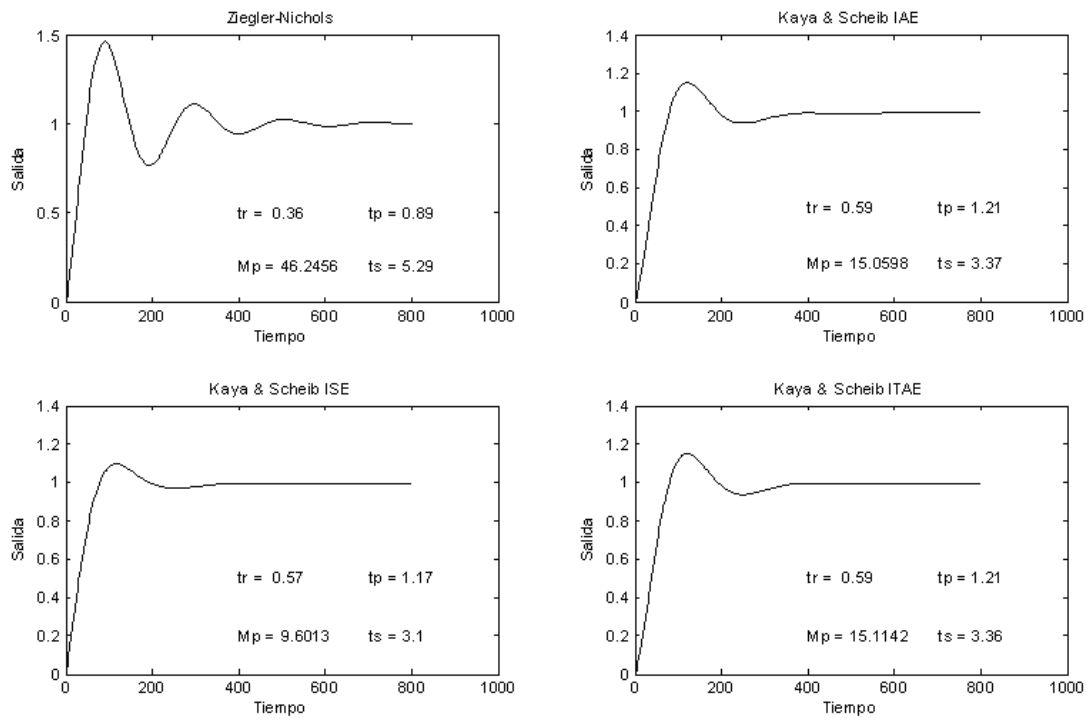

Fig. 9. Response of the system regulated by the expressions of Ziegler-Nichols and Kaya-Sheib for IAE, ISE and ITAE
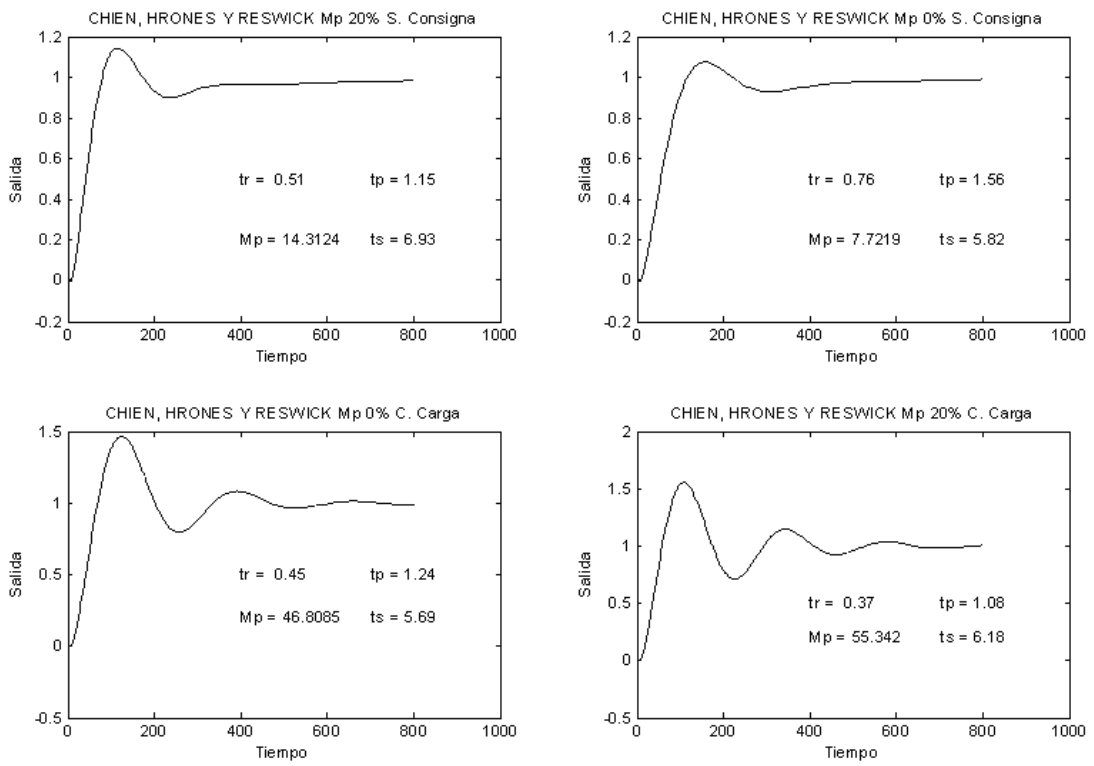

Fig. 10. Response of the system regulated by the expressions of Chien, Hrones and Reswick 


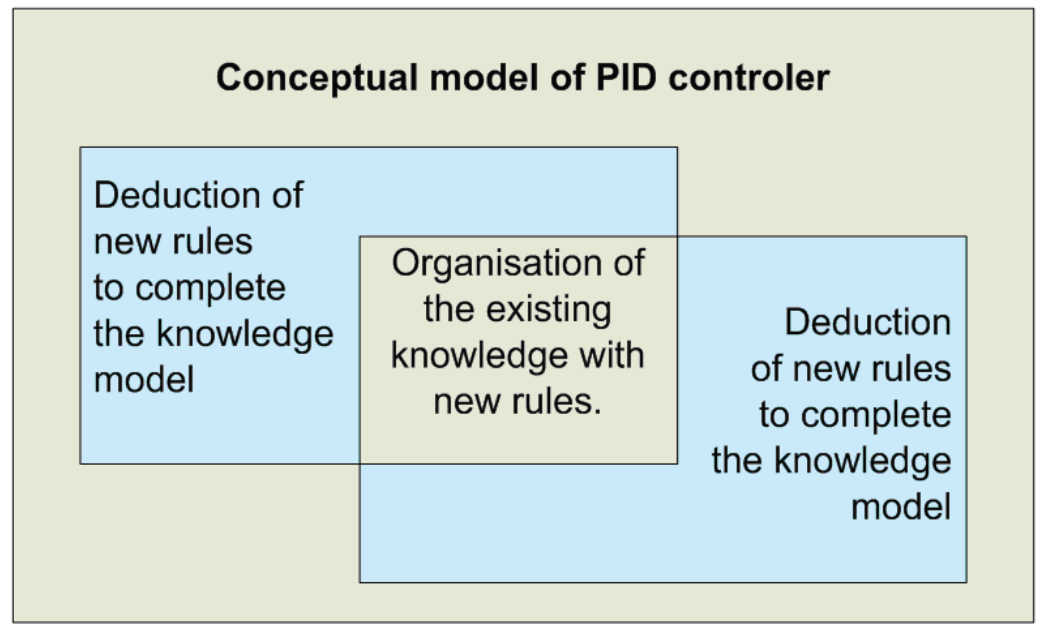

Fig. 11. General schema summarized from the conceptual model of empiric adjustment of PID regulators in open loop

- Deduction of new rules to complete the knowledge model: In this part it has been detected the necessity to deduce new rules to make a complete knowledge model, from the own system and the desired specifications, to the final derivation of the parameters of the controller in a reasoned way.

\subsection{General diagram of knowledge in the open loop}

In accordance with the steps deducted by the elaboration of the conceptual model, it is obtained a general diagram of the knowledge for the adjustment of PID controllers in open loop shown in figure 12.

Following the above a more detailed description of the knowledge schema is done, in different figures with their corresponding explanation. It starts with the corresponding part in the top right corner of the general diagram, detailed in figure 13.

In this part, the first thing to be done is to see if transfer function of the system is available. Following in both cases it is checked whether if it is a first order system with delay or if it were not the case it would not be possible to carry out the adjustment with this method. In the positive case if the transfer function is not available it concludes in the rules rg.2. If it is known the diagram of the left will be followed.

The corresponding part of the diagram of figure 14 is employed to discover if the system is a first order with delay one. For this, in first place it has to be checked if it stabilizes at a constant value with a unit step input and it is checked that there is no oscillation. If the previous is fulfilled, the next step is to check if there is a system with pure delay. With both affirmations it can be concluded that it is a system of this type, on the contrary it will not be. After having checked that it is a first order with delay system, and also the transfer function is known, the characteristics of the response $L$ and $T$ are found, and it is checked if the relation $L / T$ is found in the application range of the expression used in the case study (between 0 and 1) if it is not so, this method of design will not be applied. If the contrary applies, $L / T$ is checked to see if it is bigger than 0.1 and if positive it can be applied to all the expressions contemplated. If it is inferior than 0.1 the question to ask the user is if he/she wishes to discard 


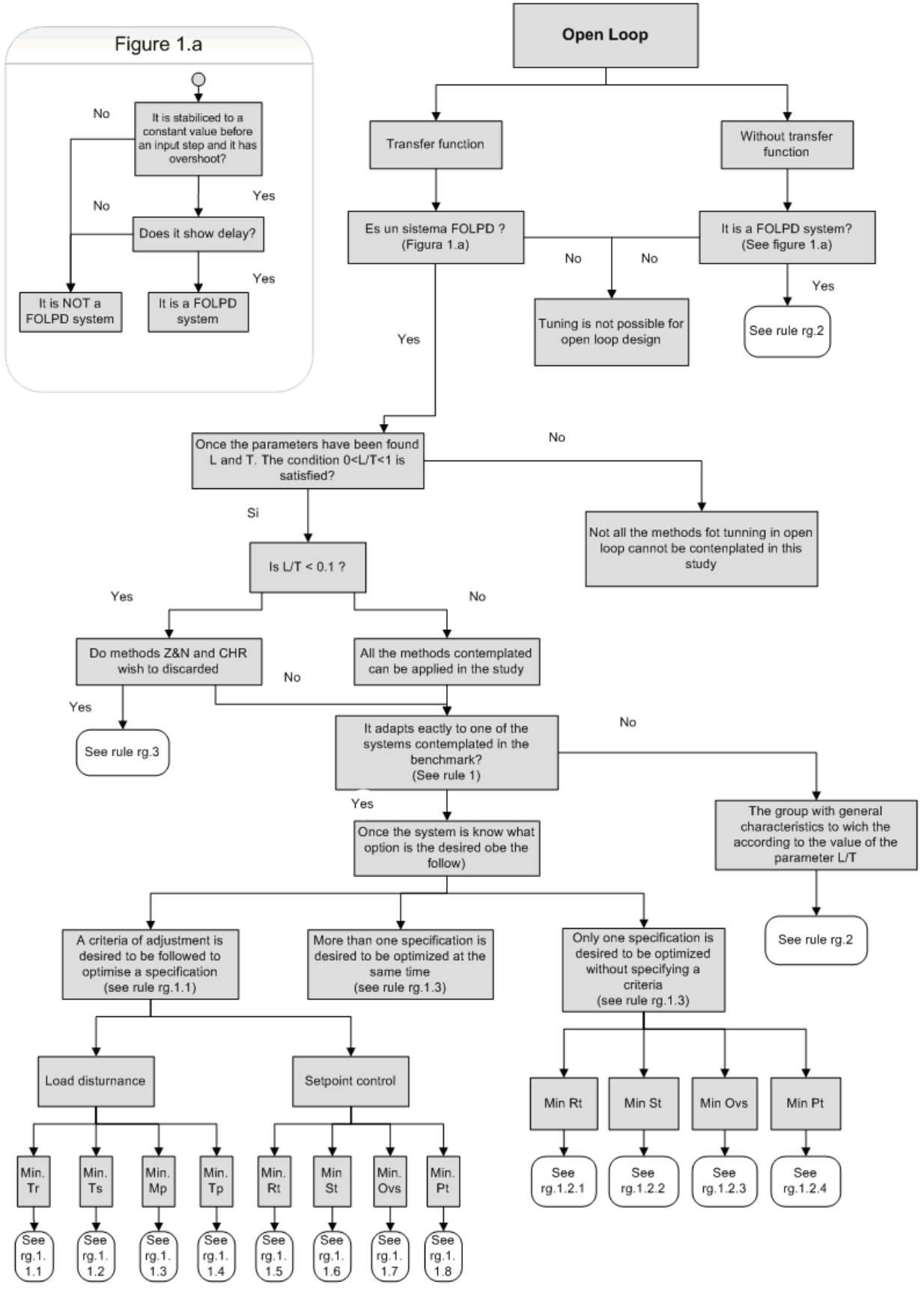

Fig. 12. General diagram of knowledge for open loop empirical tuning of PID controllers 


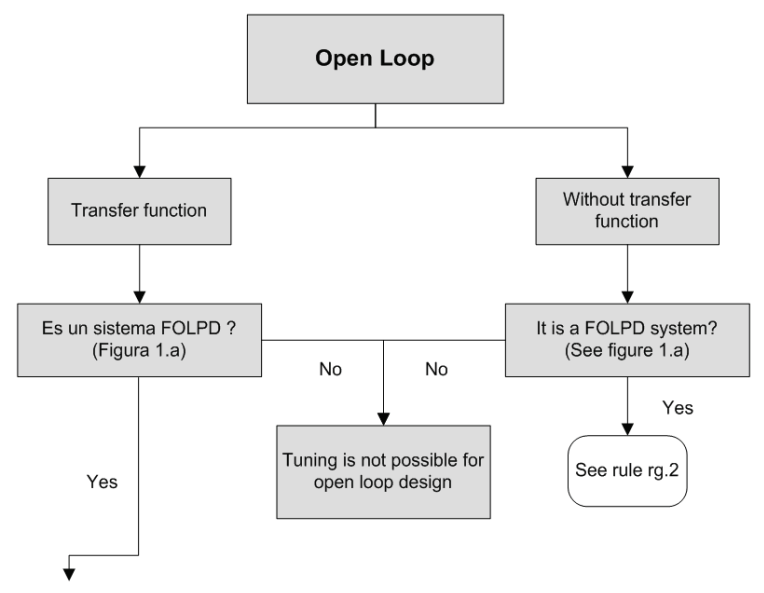

Fig. 13. Area 1 of the diagram

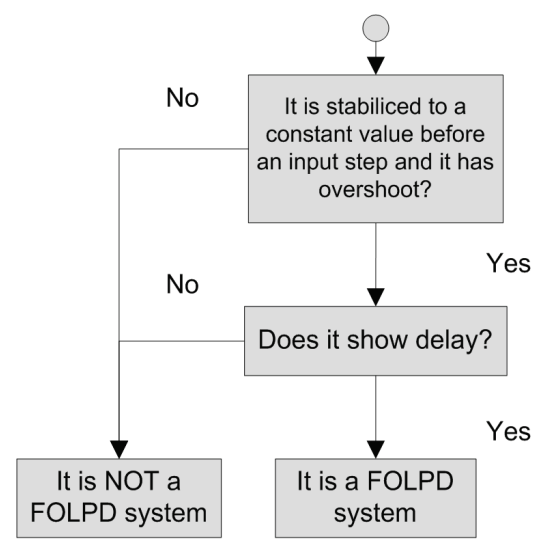

Fig. 14. Area 2 of the diagram

the expressions of Ziegler-Nichols and Chien, Hrones, Reswick for not being within its scope of application range. If they are not used it will apply rule $\mathrm{rg} .3$ and if they are used all methods will be taken into account as if $L / T$ were bigger than 0.1 .

After the checks of the diagram of figure 15, the diagram of figure 16 folows, the first check is to see if it adapts to the transfer function of the system being regulate adapts to some of the related in the Benchmark. If it is not the case it will follow the diagram by the right-hand area and it determines a group with general characteristics to which the function of relation $L / T$ belongs to, that will result with rule $r g .2$.

If the problem system adapts exactly to one of those mentioned in the Benchmark, the system is determined and it chooses one of the three following possibilities is chosen:

- Follow a criterion of adjustment (load disturbance or set point control) and also a certain specification will be optimized. And so for instance, if what wants to be done is regulate a system before changes in the load in which the objective is to optimize the response time then it will be necessary to follow rule $r g .1 .1 .1$. 


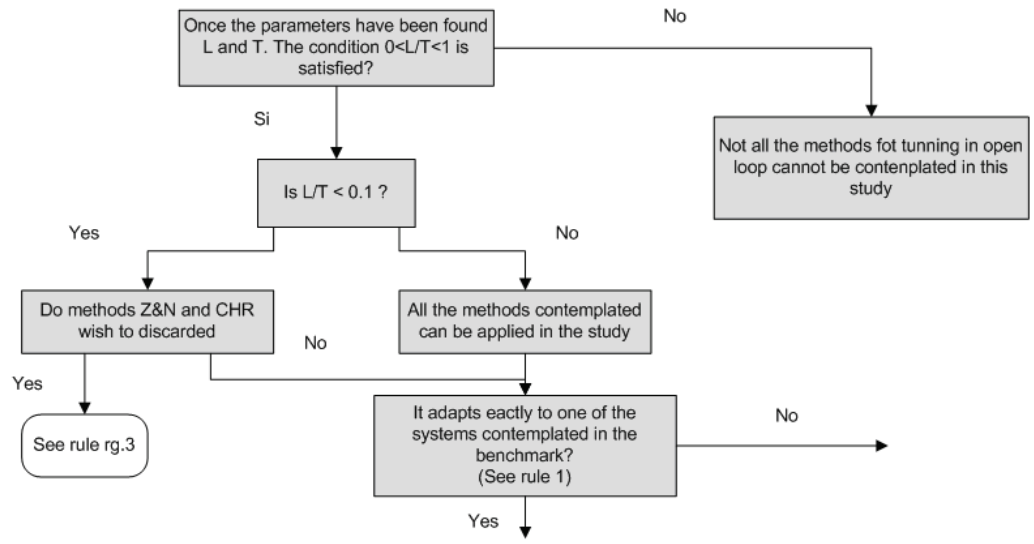

Fig. 15. Zone 3 of the diagram

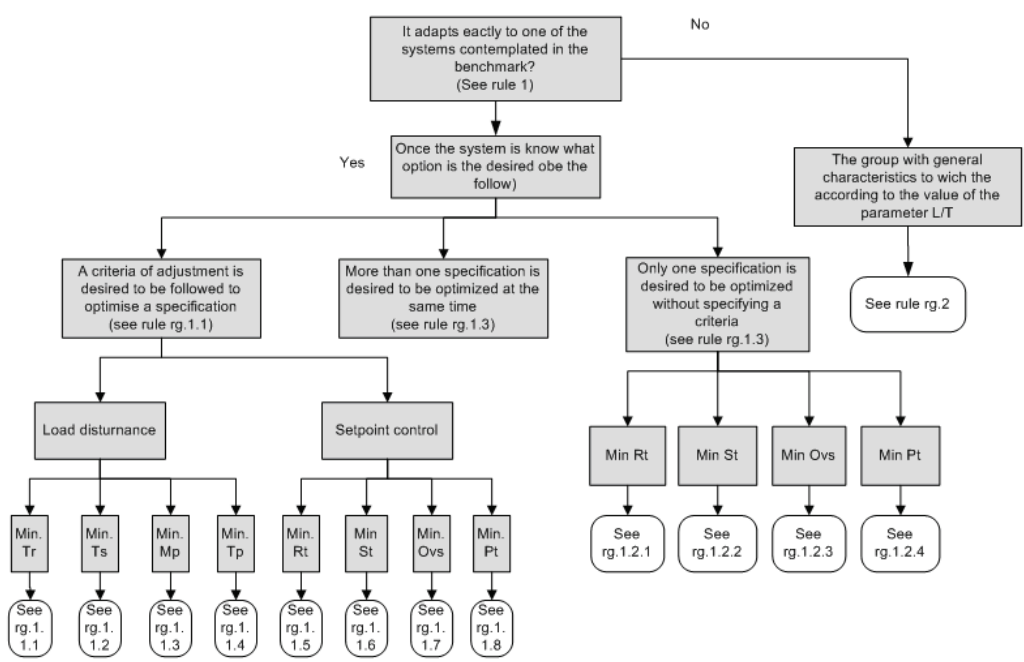

Fig. 16. Area 4 of the diagram

- If what is wanted is to optimize more than one specification simultaneously, rule $r g .1 .3$ will be followed.

- If what is wanted is to optimize an independent specification of the criteria of adjustment. For instance, if what is wanted is to minimize the settling time whether it is for load disturbance or set point control criteria, rule $r g .1 .2 .2$ will be followed.

\subsection{Deduction of rules to complete in knowledge model}

As has been commented in the general summarized schema of knowledge, it is necessary to draw new rules to complete the knowledge model: In this part the need to do a model of complete knowledge model has been detected, from the system itself and the specifications 


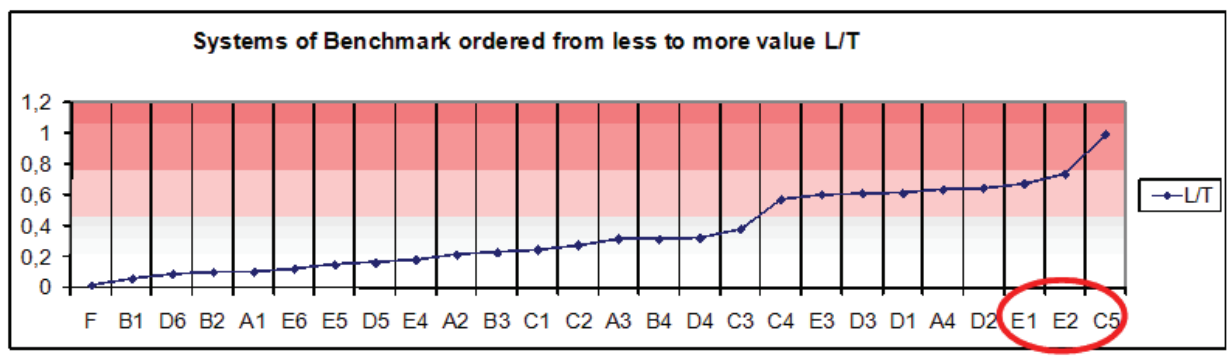

Fig. 17. Systems of Benchmark ordered from lower to higher $L / T$ value.

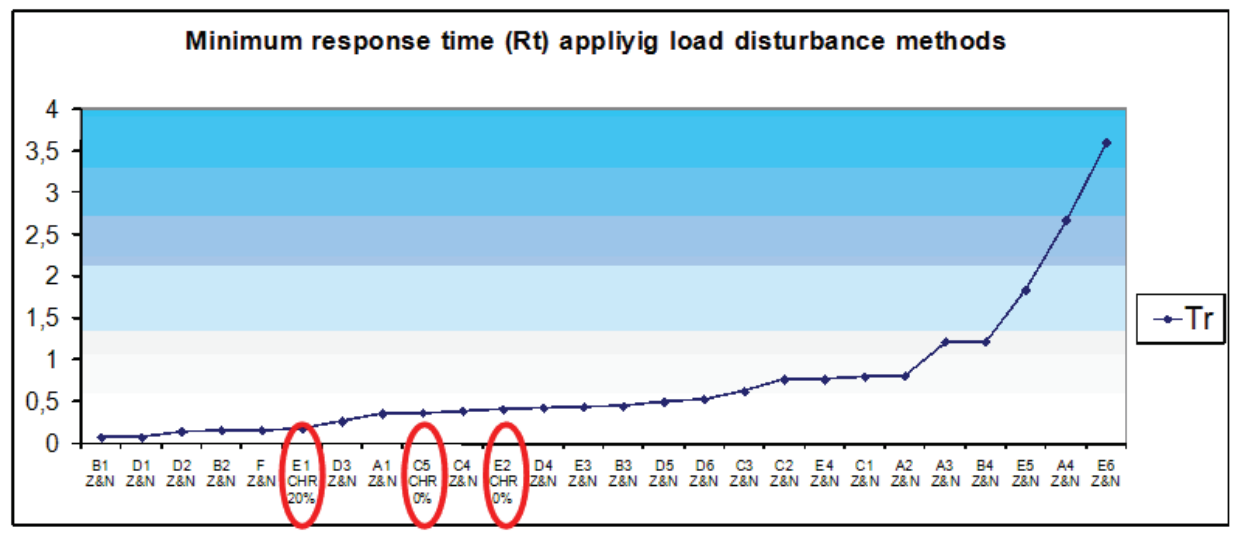

Fig. 18. Systems of Benchmark arranged from less to more value of response time for expressions with load disturbance criterion.

desired, up to the final obtaining of the parameters of the controller. In this sense two examples are shown in which the two possibilities of deduction of the rules are clarified.

\subsubsection{Deduction of the rules RG1.1.1}

It is pretended in this case to minimize the response time obtained, to regulate a system in which it is favoured the criteria of load disturbance. For this in the first place, the systems of the Benchmark are sorted lower to higher of the L/T relation, as is shown in figure 17.

Following we can see illustrated and sorted from lower to higher value of response time obtained for the expressions of changes in the load (figure 18), indicating in the graph also the expressions used in each case.

In the graph it is observed that in all cases except in three, the method of Ziegler-Nichols is employed. But contrasting the graphs 17 and 18, those systems have L/T relation similar and elevated, being all together in the end of the graph 17. And so, two rules can be established to regulate a system for load disturbance criterion, in which the time response is improved:

- If $L / T \geq 0.6763$ will apply CHR 0\% overshoot load disurbance.

- If $L / T<0.6763$ will apply Ziegler\&Nichols. 


\begin{tabular}{|c|c|c|c|c|}
\hline Siste $\mathrm{m}$ a & Mínimo Tr & Mínimo Ts & Mínima Mp & Mínim o Tp \\
\hline F & $0,16 \quad(Z \& N)$ & $1.64 \quad(Z \& N)$ & $47 \% \quad$ (CHR 0\% Mp) & $0,44 \quad(Z \& N)$ \\
\hline B1 & $0,08 \quad(Z \& N)$ & 1,01 (CHR 0\% Mp) & $45 \% \quad$ (CHR 0\% Mp) & $(Z \& N)$ \\
\hline D6 & $(Z \& N)$ & 5.19 (CHR 20\% Mp) & $45 \%$ (CHR 0\% Mp) & $(Z \& N)$ \\
\hline B2 & $(Z \& N)$ & $2,08 \quad(Z \& N)$ & $47 \% \quad(\mathrm{CHR} 0 \% \mathrm{Mp})$ & $(Z \& N)$ \\
\hline A1 & $0.36 \quad(Z \& N)$ & $(Z \& N)$ & $46 \%$ (CHR 0\% Mp) & $(Z \& N)$ \\
\hline E6 & $(Z \& N)$ & 54,01 (CHR 0\% Mp) & $46 \%$ (CHR 0\% Mp) & $(Z \& N)$ \\
\hline E5 & $1.84 \quad(Z \& N)$ & 29,27 (CHR 0\% Mp) & $47 \%(\mathrm{CHR} 0 \% \mathrm{Mp})$ & $(Z \& N)$ \\
\hline D5 & $0.5 \quad(Z \& N)$ & 6.57 (CHR 0\% Mp) & $42 \%$ (CHR 0\% Mp) & $(Z \& N)$ \\
\hline E4 & $(Z \& N)$ & $11,51 \quad(Z \& N)$ & $46 \%$ (CHR 0\% Mp) & $(Z \& N)$ \\
\hline A2 & $(Z \& N)$ & 12,87 (CHR 0\% Mp) & $45 \%$ (CHR 0\% Mp) & $(Z \& N)$ \\
\hline B3 & $0,45 \quad(Z \& N)$ & 5.88 (CHR 0\% Mp) & $45 \% \quad(\mathrm{CHR} 0 \% \mathrm{Mp})$ & $(Z \& N)$ \\
\hline C1 & $0.8 \quad(Z \& N)$ & 12,81 (CHR 0\% Mp) & $45 \%$ (CHR 0\% Mp) & $(Z \& N)$ \\
\hline C2 & $0.77 \quad(Z \& N)$ & 13,08 (CHR 0\% Mp) & $43 \%$ (CHR 0\% Mp) & $(Z \& N)$ \\
\hline A3 & $(Z \& N)$ & 21,15 (CHR 0\% Mp) & $41 \% \quad$ (CHR 0\% Mp) & $(Z \& N)$ \\
\hline B4 & $(Z \& N)$ & 21,15 (CHR 0\% Mp) & $40 \%$ (CHR 0\% Mp) & $(Z \& N)$ \\
\hline D4 & $(Z \& N)$ & 7.76 (CHR 0\% Mp) & $39 \%(\mathrm{CHR} 0 \% \mathrm{Mp})$ & $(Z \& N)$ \\
\hline c3 & $(Z \& N)$ & 13,13 (CHR 0\% Mp) & $39 \%$ (CHR 0\% Mp) & $(Z \& N)$ \\
\hline C4 & $(Z \& N)$ & 16 (CHR 0\% Mp) & $40 \%$ (CHR 0\% Mp) & $(Z \& N)$ \\
\hline E3 & $(Z \& N)$ & 14,05 (CHR 0\% Mp) & $32 \%$ (CHR 0\% Mp) & $(Z \& N)$ \\
\hline D3 & $(Z \& N)$ & 11.77 (CHR 0\% Mp) & $37 \%(\mathrm{CHR} 0 \% \mathrm{Mp})$ & $(Z \& N)$ \\
\hline D1 & $0,08 \quad(Z \& N)$ & 8.19 (CHR 0\% Mp) & $46 \%$ (CHR 0\% Mp) & $(Z \& N)$ \\
\hline A4 & $(Z \& N)$ & 68,87 (CHR 0\% Mp) & $24 \%$ (CHR 0\% Mp) & 8,86 (CHR 20\% Mp) \\
\hline D2 & $0,15 \quad(Z \& N)$ & 10 (CHR 0\% Mp) & $44 \%$ (CHR 0\% Mp) & $1,33 \quad(Z \& N)$ \\
\hline E1 & 0,18 (CHR 20\% Mp) & 10,17 (CHR 0\% Mp) & $51 \%$ (CHR 0\% Mp) & 1,53 (CHR 0\% Mp) \\
\hline E2 & 0,41 (CHR 0\% Mp) & 13,69 (CHR 0\% Mp) & $37 \%$ (CHR 0\% Mp) & 1.75 (CHR 0\% Mp) \\
\hline C5 & 0,37 (CHR 0\% Mp) & $90(\mathrm{CHR} 0 \% \mathrm{Mp})$ & $102 \%$ (CHR 0\% Mp) & 3,11 (CHR 0\% Mp) \\
\hline
\end{tabular}

Fig. 19. Groups rg.2.1. for changes in the load

The system E1 obtain its best response time using Chien, Hrones Reswick for overshoot of $20 \%$, but when CHR of $0 \%$ is employed a very small error is obtained and so the rules are generalized.

\subsubsection{Deduction of rules RG 2}

This rule as can be observed in figures 13 and 16 is applied when the transfer function is not known, also in cases where it is known but does not adapt to any of the contemplated systems in the Benchmark. From it at the same time, a classification is going to be carried out, which will become three new rules.

- Rule rg.2.1- Groups with methods for load disturbance.

- Rule rg.2.2- Groups with methods set point control.

- Rule rg.2.3- Groups with methods for both criteria.

To create the groups with general characteristics, in a similar way than the previous case, the different systems are organised from less to more value with reference to $L / T$ (figure 17). In this case, it is done in a table, because the purpose is to have generic groups in all the specifications. If for instance the case for rule rg 2.1 in which the systems are put together to follow the load disturbance criterion is shown, then refer to figure 19.

In the table the values of the specification in each case have been indicated, alongside the expressions for obtaining the parameters used to improve this specification. Next, a division 


\begin{tabular}{|l|c|c|}
\hline Comment & Number & Percent overall experiments \\
\hline $\begin{array}{l}\text { The expression } \\
\text { indicated by the }\end{array}$ & bcases & \\
rule coincides with & & \\
the one that has to & & \\
actually be used. & & \\
\hline $\begin{array}{l}\text { The expression } \\
\text { indicated by the rule }\end{array}$ & 7 cases & \\
does not coincide \\
with the one that has \\
to actually be used, \\
but the deviation is \\
very small.
\end{tabular}

Table 2. Results of the validation

in groups is made in which the systems with groups of equal expressions are concentrated. Having this in mind, for instance systems D3, D1 and $A 4$ with the condition that $0.6130<$ $L / T \leq 0.639$ (D3 to $A 4$ ), and establish the following rules:

- To minimize the Response time, the method Ziegler\&Nichols is applied.

- To minimize the Settle time, Chien, Hrones and Reswick 0\% Mp.

- To optimize the Overshoot, Chien, Hrones y Reswick 0\% Mp.

- To optimize the Peak time, Chien, Hrones and Reswick 20\% Mp.

In spite of the systems D3 and D1 the best peak time result is obtained with $\mathrm{ZN}$, if the rule for $\mathrm{CHR}$ of $20 \%$ a much smaller error is made than if the system A4 with $\mathrm{ZN}$ is regulated.

\section{Validation}

A validation of the conceptual model proposed is carried out. This will not be done on the cases in which the transfer function is known, and it is exactly adapted to one of the systems referred to in the Benchmark, but it will be carried out when the transfer function is not known or if it is known, and it does not adapt to any of the systems and also if both criteria are contemplated (load disturbance and set point control). The validation is done on 9 systems not contemplated in the Benchmark and it is checked for each one of the specifications that the model has Developer. There are a total of 36 checking cases, in which the results shown in table 2 are obtained. 
Therefore it is considered that the model proposed has a satisfactory functioning, given that the general terms are the following:

- The scores are $31 / 36=86.1 \%$

- The misses are $5 / 36=13.8 \%$

\section{Conclusions}

The task of selection of the adjustment expression to be used has been resolved with the proposed technique in the present paper, thus through the follow up of the rules procedure the adjustment expressions can be selected for the case disposed of and also choose among them if more than one is applicable.

Having selected the expression or expressions to obtain the parameters, the calculation of these is carried out, following the procedure for the case that has been chosen previously in a structured way. And so the possible paths to be followed are resolved with rules, including those to reach a balance between specifications that do not improve in one same path.

When carrying out the conceptual modelling two relevant contributions have been obtained. First, clarity has been added in various stages of the adjustment of a PID. Second, some contradictions have been manifested between different expressions that have been resolved with it.

The procedure in real plants whose function transfer is different to the ones mentioned in the Benchmark, has been validated for the more restrictive cases of the deduced rules. The results obtained and presented in the corresponding section to validating satisfy the initial objectives when verifying the functioning of the rules in the plants used.

\section{References}

Astrom, K. \& Hagglund, T. (2006). PID controllers: Theory, Desing and Tuning, Research Triangle Park, USA.

Astrom, K.J. Hagglund, T. (2000). Benchmark systems for pid control, Preprints IFAC Workshop on Digital Control. Past, present and future of PID Control, Elsevier Science and Technology, Terrasa, Spain, pp. $181-182$.

Auslander, D., Takahashi, Y. \& Tomizuka, M. (1978). Direct digital process control: Practice and algorithms for microprocessor application, Proceedings of the IEEE 66(2): 199 208.

Bennett, S. (1984). Nicolas minorsky and the automatic steering of ships, Control System Magazine Vol. 4(No. 4): 10-15.

URL: $10.1109 / \mathrm{MCS} .1984 .1104827$

Calvo-Rolle, J. \& Corchado, E. (n.d.). A bio-inspired robust controller for a refinery plant process, Logic Journal of IGPL .

URL: http://jigpal.oxfordjournals.org/content/early/2011/02/04/jigpal.jzr010.abstract

Calvo-Rolle, J.L. Alonso-Alvarez, A. F.-G. R. (2007). Using knowledge engineering in a pid regulator in non linear process control, Ingenieria Quimica 32: 21 - 28.

Chien, K.L. Hrones, J. R. J. (1952). On the automatic control of generalised passive systems, Transactions of ASME 74: 175 - 185.

Epshtein, V. (2000). Hypertext knowledge base for the control theory, Automation and Remote Control 61(11): 1928-1933. 
Feng, Y. \& Tan, K. (1998). Pideasytm and automated generation of optimal pid controllers, Third Asia-Pacific Conference on ControlEMeasurement, Aviation Industry Press, Dunhuang, China, pp. 29-33.

Kaya, A. Scheib, T. (1988). Tuning of pid controllers of different structures, Control Engineering 7: $62-65$.

Mindell, D. (2004). Between human and machine: Feedback, Control, and Computing before Cybernetics, Johns Hopkings Paperbacks edition, London.

Pang, G. (1991). An expert adaptive control scheme in an intelligent process control system, Proceedings of the IEEE International Symposium on the intelligent Control, IEEE Press, Arlington, Virginia, pp. 13-18.

Pang, G. (1993). Implementation of a knowledge-based controller for hybrid systems, Decision and Control, 1993., Proceedings of the 32nd IEEE Conference on, IEEE Press, San Antonio, TX, USA, pp. $2315-2316$ vol.3.

Pang, G., Bacakoglu, H., Ho, M., Hwu, Y., Robertson, B. \& Shahrrava, B. (1994). A knowledge-based system for control system design using medal, Computer-Aided Control System Design, 1994. Proceedings., IEEE/IFAC Joint Symposium on, IEEE Press, Tucson, AZ , USA, pp. $187-196$.

Wilson, D. (2005). Towards intelligence in embedded pid controllers, Proceedings of the Eight IASTED International Conference on Intelligent Systems and Control, ACTA Press, Cambridge, USA, pp. 25-30.

Zhou, L. Li, X. H. T. \& Li, H. (2005). Development of high-precision power supply based on expert self-tuning control, ICMIT 2005: Control Systems and Robotics, SPIE-The International Society for Optical Engineering, Wuhan, China, pp. 60421T.1-60421T.6.

Ziegler, J. Nichols, N. R. N. (1942). Optimum settings for automatic controllers, Transactions of ASME 64: $759-768$. 


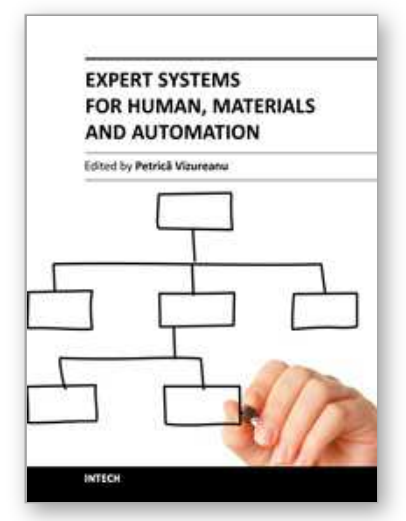

\author{
Expert Systems for Human, Materials and Automation \\ Edited by Prof. PetricÄ $f$ Vizureanu
}

ISBN 978-953-307-334-7

Hard cover, 392 pages

Publisher InTech

Published online 10, October, 2011

Published in print edition October, 2011

The ability to create intelligent machines has intrigued humans since ancient times, and today with the advent of the computer and 50 years of research into Al programming techniques, the dream of smart machines is becoming a reality. The concept of human-computer interfaces has been undergoing changes over the years. In carrying out the most important tasks is the lack of formalized application methods, mathematical models and advanced computer support. The evolution of biological systems to adapt to their environment has fascinated and challenged scientists to increase their level of understanding of the functional characteristics of such systems. This book has 19 chapters and explain that the expert systems are products of the artificial intelligence, branch of computer science that seeks to develop intelligent programs for human, materials and automation.

\title{
How to reference
}

In order to correctly reference this scholarly work, feel free to copy and paste the following:

José Luis Calvo-Rolle, Ramón Ferreiro García, Antonio Couce Casanova, Héctor Quintián-Pardo and Héctor Alaiz-Moreton (2011). Conceptual Model Development for a Knowledge Base of PID Controllers Tuning in Open Loop, Expert Systems for Human, Materials and Automation, Prof. PetricÄf Vizureanu (Ed.), ISBN: 978953-307-334-7, InTech, Available from: http://www.intechopen.com/books/expert-systems-for-humanmaterials-and-automation/conceptual-model-development-for-a-knowledge-base-of-pid-controllers-tuning-inopen-loop

\section{INTECH}

open science | open minds

\section{InTech Europe}

University Campus STeP Ri

Slavka Krautzeka 83/A

51000 Rijeka, Croatia

Phone: +385 (51) 770447

Fax: +385 (51) 686166

www.intechopen.com

\section{InTech China}

Unit 405, Office Block, Hotel Equatorial Shanghai

No.65, Yan An Road (West), Shanghai, 200040, China

中国上海市延安西路65号上海国际贵都大饭店办公楼 405 单元

Phone: $+86-21-62489820$

Fax: $+86-21-62489821$ 
(C) 2011 The Author(s). Licensee IntechOpen. This is an open access article distributed under the terms of the Creative Commons Attribution 3.0 License, which permits unrestricted use, distribution, and reproduction in any medium, provided the original work is properly cited. 